\title{
Geography of human capital in Italy: a comparison between macro-regions
}

\author{
Alberto Baldissera and Federica Cornali* \\ Department of Cultures, Politics and Society, University of Turin, Turin, Italy
}

(Received 20 September 2018; final version accepted 7 April 2020)

\begin{abstract}
Interest in the spread of human capital has grown in recent decades, as it is acknowledged to play an increasingly important role in supporting social and economic development. This paper, starting from the distinction between education - assessed by educational attainment - and literacy proficiency - that is, what people are actually able to do with the written word - examines the distribution of these properties in Italy. Results of analysis show that while the longstanding gap between the North and the South is gradually closing with regard to the distribution of educational credentials, there is still a significant difference in the acquired level of competence. There is also an unexpected result: the regions of the North-West, once the main driver of Italy's economic development, today deploy a smaller stock of human capital than the North-East and Central macroregions. In light of these findings, improving the education system's effectiveness and creating adequate political, institutional and legal arrangements that favour the development of human capital appear to be an absolute priority for Italy.
\end{abstract}

Keywords: human capital; educational attainment; assessment of adult competencies; regional divide.

\section{Introduction}

In Italy, the stratified distribution of human capital, though assiduously debated, remains an unresolved puzzle: composite inequalities between genders, generations and socio-economic-cultural conditions create a multidimensional and variegated scenario, the complexity of whose phenomena and causal links must be acknowledged. The most recent sociological research has mainly concerned the relationship between social origins and educational opportunities. However, it has not yielded conclusive results. According to some authors, the inequality in educational opportunities reflects the main social fractures and is stable across cohorts (Pfeffer 2008; Triventi and Trivellato 2008; Manzo 2009). Other authors, however, maintain that this inequality is shrinking: we are witnessing a long-term trend of notable intensity, which is not limited to a single social class and concerns all levels of education (Barone, Luijkx and Schizzerotto, 2010; Barone and Guetto 2016). However, educational opportunities are influenced not only by social origin. Gender and birth cohort are equally important sources of variation. In particular, this paper will consider the subnational variance, that is to say the inequality in the performance of a school system on a geographical basis. Breen and Jonsson (2007) note that this type of variance should not be overlooked, since the variation in school expansion and its change over time in individual countries are of fundamental interest in determining whether equalisation objectives have in fact been achieved.

\footnotetext{
* Email: federica.cornali@unito.it
} 
School systems are among the largest and most complex organisations, which feature loosely coupled structures (Weick 1976) and composite cultural dimensions (Martin 1992). For these reasons, school systems frequently show a lack of internal uniformity. The problem of geographical variance is thus significant, and common to many advanced countries. For the most part, it can be seen in countries with different sub-national education policies (e.g. England, Wales and Scotland in the United Kingdom), or in countries with linguistic differences, sometimes combined with significant economic differences (e.g. Flanders and Wallonia in Belgium).

The Italian school system, with a total of over 56,000 schools, 370,000 classes, almost one million teachers and eight million students, is ostensibly uniform in both legislative and administrative terms throughout the country. However, this uniformity is illusory, as it masks significant geographical variations in the system's performance (Checchi and Peragine 2005; Foresti and Pennisi 2007; Baldissera, Bianco and Cornali 2012; Asso, Azzolina and Pavolini 2015). The geographical gap in the Italian education system's outcomes has long been familiar, and has been addressed by numerous studies. Analysing the data from the first wave of the ILFI (Longitudinal Survey on Italian Families), Pisati (2002) showed that residents in the North are more likely than residents in the South to finish compulsory schooling. However, southern residents who finish compulsory schooling are more likely to enrol in higher education courses and also, despite a higher drop-out rate in upper secondary school, to enter university. Ballarino, Panichella and Triventi (2014) note that over the past few decades the wide gap in school participation between North and South has narrowed as regards lower levels of education. However, in the upper secondary and tertiary levels, it seems that the North-South divide has widened in recent decades, despite a slight decrease during the 1970s. Studies have thus yielded conflicting findings. This could depend on sample size, the fact of examining different generational cohorts, the use of particular analysis techniques, or the adoption of different interpretive schemes.

The many aspects of sub-national variance thus deserve further scrutiny. In addition to analysing the geographical distribution of level of education certified by educational attainment, it is also useful to analyse what people are actually able to do with the written word. This paper examines the variance of these phenomena in four Italian macro-regions. Regarding the educational attainment, we refer to the official data issued by the Italian National Institute of Statistics (ISTAT) and the Ministry of Education, Universities and Research (MIUR). As far as level of competence is concerned, we will refer to the results of the tests administered between 2011 and 2012 to the Italian sample in the most recent OECD Survey of Adult Skills programme, PIAAC (Programme for the International Assessment of Adult Competencies). ${ }^{1}$

The picture that emerges from this analysis corroborates situations that have been known for some time, but also reveals certain important unexpected aspects. Southern Italy's weakness is confirmed, though its recent progress in terms of formal education levels brings that area closer to the results of the other macro-regions. The main unexpected result is the critical situation in the North-West regions - those that until the 1980s were considered the 'locomotives of Italian industrial development'. Subsequent investigations have shown that although educational qualifications are still paramount in the individual's endowment of human capital, the geographical variable - and its impacts on the effectiveness of the educational systems and the different levels of social and economic dynamism - also has a major influence. In conclusion, we will present some hypotheses and conjectures about these findings and discuss several problems. 


\section{The expansion of education in Italy}

Education has become almost universal in the economically advanced countries. Since the end of the Second World War, school policies, supported unanimously by public decision-makers, have centred on expansion: more students, more schools, more teachers, more educational qualifications awarded. Today participation in upper secondary education has almost reached saturation levels. We are also witnessing the rapid diffusion of tertiary education (Meyer, Ramirez and Soysal 1992; Schofer and Meyer 2005). The drive for expansion, though it has been accompanied over the years by qualitative objectives, has never been abandoned. ${ }^{2}$ Over time, the most advanced countries have thus tended to converge as regards higher standards of education.

Italy has participated in this process by bridging the gap with other countries, chiefly thanks to the rapidly rising percentage of young people who graduate from upper secondary school. In the last ten years, it has increased by more than 20 points, reaching over 80 per cent. This convergence, however, stops if we look at the data for tertiary education: the percentage of college graduates is in fact comparatively small (to date it is about 13 points below the European average in the 30-34 age group) (OECD 2016a).

Italy's progress towards the levels of education typical of advanced countries has been slow, difficult and, as we can affirm, still far from complete. This is presumably due to the high rates of illiteracy that have afflicted the country for centuries. During the first postwar census in 1951, 12.9 per cent of the population stated that they were unable to read and write. This percentage, added to the 46.3 per cent of those who, while claiming to be literate, admitted that they did not have any formal educational qualification, testified to the profound cultural backwardness of the country. However, the average figure conceals the great internal differences that existed. In some northern regions the percentage of functional illiterates was rather low (e.g. 8.7 per cent in Trentino-Alto Adige, 12 per cent in Lombardy) while in the South and Islands this percentage was very high (57 per cent in Calabria, 51 per cent in Basilicata, 48 per cent in Sardinia, 47 per cent in Sicily and Campania).

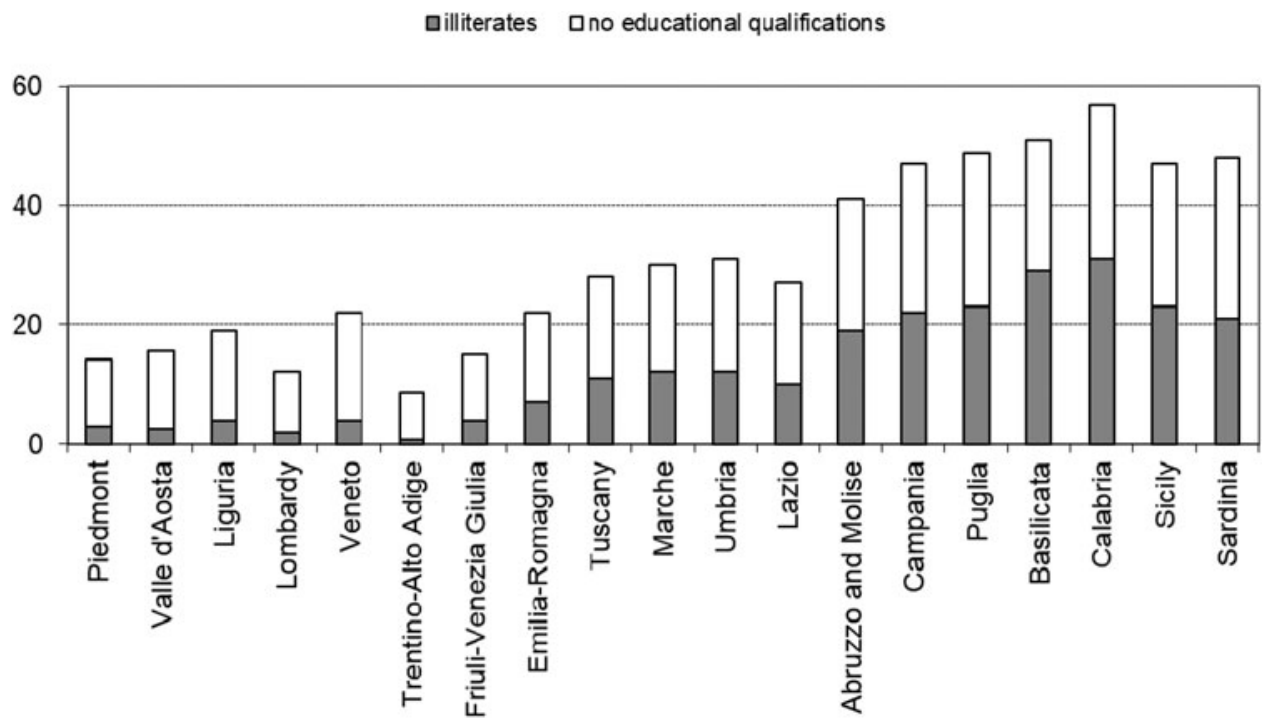

Figure 1. Percentages of illiterates and people with no educational qualifications in various Italian regions, 1951 census. Source: De Fort 1995. 
As these data make clear, Italy's process of convergence towards high standards of education in the population has also played out on an internal front: that of bridging the gap between the different regions, in particular between those of the North and those of the South.

\section{Beyond convergence? A comparison between Italian macro-regions}

The most recent national education statistics show no significant differences in the performance of the school system in the various areas of Italy. For example, they do not indicate any particular imbalance in the educational provision, nor in the student-to-teacher ratio in the different levels of education. If we look at certain indicators of effectiveness, the comparison between regions reveals a number of contrasts. Indicators that signal the recent progress achieved by the school system in the South and which have even enabled it to out-perform the central and northern regions in some cases, are flanked by others that confirm that the South is lagging behind.

We start with young people's participation in the school system. In Italy, compliance with compulsory schooling requirements - the so-called obbligo d'istruzione ${ }^{3}$ - is such that attendance at the basic education cycles is almost universal. According to the Italian National Register of Students, only 0.08 per cent of students of primary school age, 0.20 per cent of lower secondary school age and 1.24 per cent of upper secondary school age evaded compulsory schooling in the 2011-2012 school year. The risk of abandoning compulsory education is higher in the South. For lower secondary schools, Sicily, Sardinia and Campania are the regions with the highest drop-out rates ( 0.47 per cent, 0.41 per cent and 0.36 per cent respectively), followed by Puglia (0.29 per cent) and Calabria (0.19 per cent). In some metropolitan areas, this percentage is even higher. The general school dropout index produced by the Palermo Province Observatory - which summarises indicators for abandonment, non-admissions and withdrawals - indicates that one child in a hundred did not attend primary school and more than one in seven did not attend lower secondary school in the metropolitan area during 2011. Early school leaving is more evident during the years of the so-called obbligo formativo. ${ }^{4}$ It mainly concerns secondary school, especially in the third and fourth year of technical and vocational schools. The evening courses of second-level institutions deserve special mention, as they are attended almost exclusively by working students, whose drop-out rates are very high. Despite this, in recent decades the post-compulsory schooling rate, calculated as the ratio of students enrolled in upper secondary school to the population aged between 14 and 18, continued to show sustained growth, particularly in the South (see Table 1).

Table 1. Post-compulsory schooling rate (a) and percentage variation in secondary schools (state and non-state) from 1984 to 2014 in Italian macro-regions

\begin{tabular}{|l|c|c|c|c|c|}
\hline & $\mathbf{1 9 8 4}$ & $\mathbf{1 9 9 4}$ & $\mathbf{2 0 0 4}$ & $\mathbf{2 0 1 4}$ & Variation 1984-2014 \\
\hline North-West & 55.6 & 78.2 & 88.5 & 85.4 & +29.8 \\
\hline North-East & 56.1 & 80.6 & 90.6 & 90.5 & +34.4 \\
\hline Central Italy & 65.3 & 88.2 & 98.8 & 97.5 & +32.2 \\
\hline South and Islands & 51.4 & 73.6 & 92.1 & 97.3 & +45.9 \\
\hline
\end{tabular}

(a) Ratio of students enrolled in secondary school to the 14-18-year olds population Source: http://seriestoriche.istat.it/ 
Over time, the significant increase in the rate of participation in upper secondary education has brought the South level with and even ahead of the rest of the country in the number of students enrolled and high school graduates. Out of 100 nineteen-year-olds, 71.2 obtain a diploma in the North-West, 74.6 in the North-East, 80.8 in Central Italy and 79 in the South and Islands (ISTAT 2015). These data show that school system performance in the South has apparently equalled or exceeded that of the other Italian macro-regions (in this regard, see also Felice 2012). However, there is no lack of contrasting evidence. In particular, the proportion of young people aged 15 to 29 who are Not in Education, Employment or Training (NEET) is particularly high in the South. In the international rankings, Italy is second only to Greece in this respect: the percentage of NEETs is more than ten points above the European average ( 26 per cent vs. 15.9 per cent). The situation is particularly alarming in six southern regions: Sicily (39.7 per cent), Campania (36.4 per cent), Calabria (35.6 per cent), Puglia (34.1 per cent), and Sardinia and Basilicata (31.8 per cent). Two regions in the North-West are also in a critical condition: Piedmont (22.7 per cent) and Liguria (21.1 per cent) (ISTAT 2015).

Data concerning participation in the university system are also conflicting. After remaining behind for years, the South and Islands finally caught up with, and even outstripped, the North's university enrolment in the first years of the second millennium. However, it was a temporary advantage. In fact, while the proportion of students who went on to university after high school in the South and Islands was slightly higher than the Italian average in 2004 (75 per cent vs. 72.3 per cent), it had once more fallen behind by 2014 (44.7 per cent vs. 49.1 per cent).

Lastly, a few words are in order concerning public spending in education, which in Italy is notoriously low. In 2012, it accounted for 4.1 per cent of gross domestic product (Eurostat 2012), lower than that of other major European countries (Denmark 7.9 per cent, Sweden 6.8 per cent, France and the United Kingdom 6.1 per cent, Austria 5.6 per cent, Germany 4.3 per cent). In this respect, the South is less disadvantaged. Calabria, Sicily, Campania, Basilicata and Puglia are the regions with the highest public expenditure in education and training as a percentage of GDP: between 6.1 per cent and 7.2 per cent, according to the most recent data provided by ISTAT (2011). In central and northern areas, the Valle d'Aosta (5 per cent of GDP) and the self-governing provinces of Trento ( 4.7 per cent) and Bolzano ( 4.8 per cent) are above the average for the geographical area to which they belong. The lowest spending is found in Lombardy (2.5 per cent), Emilia-Romagna (2.6 per cent), Veneto (2.7 per cent), Friuli Venezia-Giulia (2.9 per cent), Piedmont (3.1 per cent) and Liguria (3.0 per cent). Southern Italy's higher percentage of public spending on education is the result of several factors: a larger proportion of the population is of school age, a much lower percentage of students is enrolled in private schools than in the North, and there are higher numbers of teaching and non-teaching staff. Furthermore, it should be borne in mind that the South has benefited in recent years from additional resources, in particular from the Fund for Under-Utilised Areas (FAS), which provides additional national resources on top of ordinary funding and Community co-financing. ${ }^{5}$

\section{From educational attainment to competence}

The data show a general improvement in the performance of the Italian education system and, in particular, that the South is gradually catching up with other macro-regions. This trend, which has been underway for some years, can thus be presumed to have increased human capital and made it more uniformly allocated. Although educational attainment can be a useful tool for empirically approximating the stock of available human capital, it is important to bear its limitations in mind. In fact, it does not specify what knowledge, skills and competencies are learned, under 
what conditions and at what level of mastery; likewise, it does not consider the devaluation of acquired knowledge and abilities through obsolescence or failure to remember. Lastly, it ignores non-formal education, or the learning that takes place 'outside' the academic path as well as enterprise-based training. For these reasons, to determine how much of Italy's sub-national variance has in fact been reduced, we will move from an examination of educational attainment to an examination of competence level, that is to say, the results of a survey of a sample of 4,621 Italians between 16 and 65 years of age, carried out by the Programme for the International Assessment of Adult Competencies (PIAAC). ${ }^{6}$ This survey estimated the key information-processing competencies that are relevant to adults in many social contexts and work situations, and necessary for fully integrating and participating in the labour market, education and training, and social and civic life (OECD 2013, 25). It directly measured proficiency in several information-processing skills - literacy, numeracy and problem solving in technology-rich environments. The results are represented on a 500-point scale, and the interviewees were classified according to their scores in six different proficiency levels in each domain (Levels 1 through 5, plus below Level 1).

To use the data from the PIAAC survey more effectively, we decided to consider only the domain considered most pertinent to the purposes of this study, namely literacy, defined as 'the ability to understand, evaluate, use and engage with written texts to participate in society, to achieve one's goals, and to develop one's knowledge and potential' (OECD 2016b, 59). Therefore, the analyses presented in this paper will focus on the score obtained by the interviewees in the literacy tests, as representative of the possession of the main communication tool to access and process information and to build new knowledge. The cases were weighed with the special variable present in the database (Final Full Sample Weight) prepared to re-proportion the sample with respect to the Italian population.

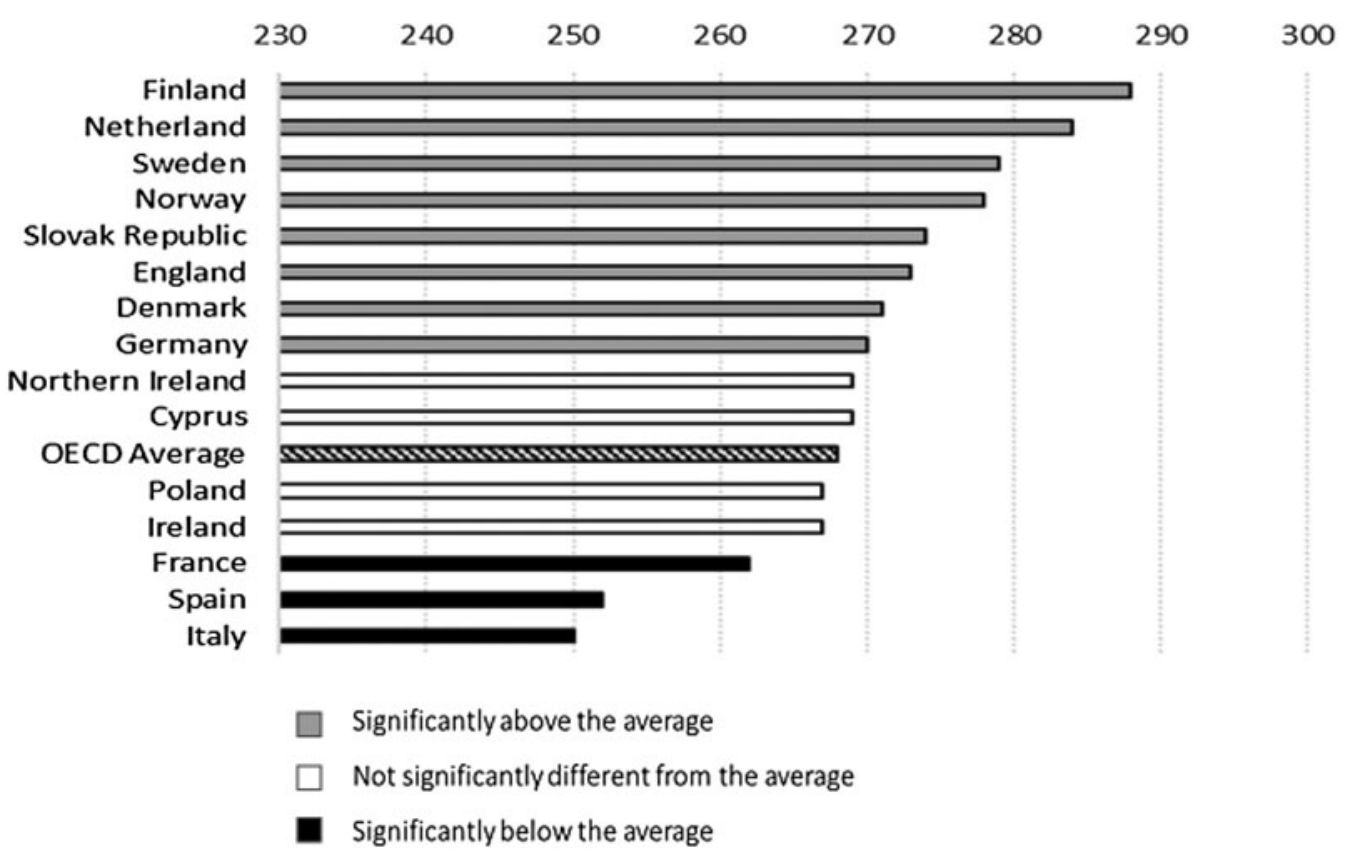

Figure 2. Mean literacy proficiency scores in several OECD Countries.

Source: OECD 2013. 
As shown in Figure 2, Italy's performance on the PIAAC survey is generally modest by comparison with the OECD average or other countries of similar socioeconomic development.

\section{A persistent gap between Italy's macro-regions}

To gauge the geographical variability considered in this paper, we will look at how the literacy proficiency scores are distributed across Italy's macro-regions (see Table 2$)^{7}$

Table 2. Literacy proficiency scores in the Italian macro-regions

\begin{tabular}{|l|c|c|c|c|}
\hline & Mean & S.D. & Min & Max \\
\hline North-West & 248.54 & 47.18 & 91.67 & 371.28 \\
\hline North-East & 260.46 & 41.52 & 130.30 & 438.64 \\
\hline Central Italy & 260.87 & 42.53 & 98.97 & 410.92 \\
\hline South and Islands & 241.58 & 42.53 & 101.10 & 357.75 \\
\hline Italy & 250.76 & 44.40 & 91.67 & 438.64 \\
\hline
\end{tabular}

$\mathrm{F}=77.59$ Sign. $=0.000$

Source: Authors' calculation from PIAAC dataset (2011-2012).

The findings ${ }^{8}$ in Table 2 show the scarcity of literacy proficiency available in the South and a poor average level in the North-West. In the latter area, the standard deviation is higher, even in the absence of excellent performance. The North-East has a slightly lower average than that of Central Italy, a lower measure of dispersion, and a range of variation of scores tending towards the top. The expected convergence between North and South is not observed.

As the performance of the South's school system has only recently improved, improvements could be limited to the younger cohorts. This hypothesis is only partially confirmed by the distribution of the literacy proficiency scores by macro-region and age group: young people in the South have better skills than adults and the elderly, but average scores are negative and are still far from those of the same cohorts in other areas of Italy (see Table 3).

Table 3. Mean literacy proficiency scores by age groups and Italian macro-regions

\begin{tabular}{|l|c|c|c|c|c|}
\hline & $\mathbf{1 6}-\mathbf{2 5}$ years & $\mathbf{2 6 - 3 5}$ years & $\mathbf{3 6 - 4 5}$ years & $\mathbf{4 6 - 5 5}$ years & 56-65 years \\
\hline North-West & 258.60 & 267.86 & 247.18 & 242.23 & 227.06 \\
\hline North-East & 266.88 & 270.41 & 267.43 & 253.37 & 243.08 \\
\hline Central Italy & 278.81 & 259.96 & 261.03 & 263.04 & 244.40 \\
\hline South and Islands & 255.47 & 248.90 & 243.12 & 236.15 & 220.70 \\
\hline Italy & 269.94 & 261.79 & 254.69 & 248.70 & 233.81 \\
\hline
\end{tabular}

$\mathrm{F}=94.15$ Sign. $=0.000$

Source: Authors' calculation from PIAAC dataset (2011-2012).

In all areas, the 56-65-year-old age group shows the lowest scores, most likely in relation to a low level of education. Trends in other age brackets are not uniform across macro-regions. In the 
North-West and in the North-East, the 26-35 age bracket recorded the highest scores. Probably its members have higher levels of educational qualifications and have been able to benefit from on-the-job learning, unlike the younger group (16-25-year-olds) whose members, in addition to still having to finish their training, probably had fewer opportunities for work experience. The situation changes for the 36-45 age bracket, which is the middle cohort and is generally the most productive. The average score of respondents in this age group shows the level of human capital is clearly lower in the North-West than in the North-East and Central Italy. In Central Italy, the youngest age bracket (16-25-year-olds) shows the highest average score. Even the most mature segments (46-55 and 56-65-year-olds) stand out for comparatively better performance. In the South and in the Islands, the average scores are below average in all age groups, except for the younger brackets.

We will now examine how the various educational qualifications in the four Italian macroregions correspond in terms of literacy proficiency (see Table 4).

Table 4. Mean literacy proficiency scores by educational qualifications and macro-regions

\begin{tabular}{|l|c|c|c|c|}
\hline & $\begin{array}{c}\text { Primary } \\
\text { education }\end{array}$ & $\begin{array}{c}\text { Lower Secondary } \\
\text { education }\end{array}$ & $\begin{array}{c}\text { Upper Secondary } \\
\text { education }\end{array}$ & $\begin{array}{c}\text { Tertiary } \\
\text { education }\end{array}$ \\
\hline North-West & 202.61 & 236.82 & 265.14 & 290.19 \\
\hline North-East & 230.35 & 249.66 & 274.47 & 294.07 \\
\hline Central Italy & 220.37 & 252.48 & 268.30 & 286.76 \\
\hline $\begin{array}{l}\text { South and } \\
\text { Islands }\end{array}$ & 202.32 & 237.67 & 255.05 & 264.47 \\
\hline Italy & 213.90 & 244.15 & 265.74 & 283.87 \\
\hline
\end{tabular}

$\mathrm{F}=474.80$ Sign. $=0.000$

Source: Authors' calculations from PIAAC dataset (2011-2012).

As expected, there is an association between educational qualifications and the literacy proficiency. The trend is consistent: the scores increase along with the level of education and reach, in all age brackets, the mean values at upper secondary education. The outcomes are particularly poor in the South and in the Islands: the scores are lower than those of other regions in all levels of education. Not only that: holders of tertiary education degrees at the first and second level obtain lower scores than people with lower educational qualifications in other macro-regions. The critical situation in the North-West is also confirmed: respondents at all levels of education in this macroregion have lower average scores than in the North-East and Central Italy. The less educated (primary and lower secondary education) bring down the area's overall average, and holders of upper secondary qualifications are unable to compensate. The North-West's immigrant population, moreover, has a particularly low average score: 213.80 as against 264.40 in the North-East, 264.23 in Central Italy and 233.77 in the South and Islands. Plausibly, this could be explained by the reduced capacity of this area to attract the most competent immigrants. However, this is not a satisfactory explanation, since even those immigrants from 0 to 5 years of age fully educated in Italian schools have scores lower than the national average and lower than those of all the other macro-regions (239.60 compared to 275.15 in the North-East, 269.90 in Central Italy and 268.31 in the South and Islands). Given the singularity of this situation, which needs to be addressed by specific studies, we chose not to include this sub-population in the analyses and comments that follow. 


\section{Where does human capital come from?}

Though education has a fundamental role in forming individual human capital, other factors are also relevant. To identify them in the sample, we performed a multiple linear regression in which the dependent variable is the literacy proficiency score. As sources of variation, we considered age, gender, the macro-region of residence, educational qualification and employment status. The educational qualification was determined according to the International Standard Classification of Education (ISCED-1997) and reclassified as low level (elementary education or no qualification), medium level (lower secondary education, upper secondary education) and high level (tertiary education). The employment status was determined according to the International Standard Classification of Occupations (ISCO-2008) and reclassified as highly qualifed professionals, clerks and technicians, skilled manual workers, and elementary occupations, to which are added other non-professional conditions such as being a student, unemployed, retired or fulfilling domestic tasks or looking after children/family. As background status proxies, the variable concerning the education level of the father was taken into account, and according to the ISCED-1997 reclassified as high, medium and low level of education. The values of the coefficients up to the model are shown in Table 5.

Predictably, regression analysis confirms the importance of age, education and profession in the distribution of literacy proficiency. The model consistently shows that being young, welleducated and with a high professional position predicts a high level of proficiency. Furthermore, the analysis confirms the arguments advanced in an extensive literature (see e.g., OECD 2016b) regarding the importance of parents' educational attainment in predicting individual literacy proficiency. Lastly, as regards the main focus of this study, the analysis confirms the relevance of geographical variability. However, by testing interaction effects between macroregion and level of education of the person interviewed, results obtained are non-significant. These latter outcomes alert us to the risk of inferring individual results, in this case the literacy proficiency score, starting from aggregated data, such as those referring to belonging to a macroregion. In connecting two different levels of analysis it is therefore necessary to reflect on the nature of the data but also to explore the sociological and contextual specificity of the spatial units referred to. In fact, each territorial unit includes specific ecological effects.

\section{The South's backwardness}

The PIAAC data show that the results achieved in competence tests by residents of the South and the Islands are consistently below those found in other macro-regions. This is a strong trend, with a difference in test scores that corresponds roughly to the gap between Italy and the rest of the OECD sample. Such a gap can be seen in all the sub-groups of the sample (by age, level of education and employment status).

The literature offers three main interpretations of the geographical variance in the distribution of human capital in Italy. The first, or reductionist, interpretation attributes the gap primarily, if not exclusively, to the school system. The second interpretation, on the other hand, centres on the so-called 'Southern question', or in other words on the economic, political and social disadvantage of the South compared to the rest of the country. Frequently, this interpretation emphasises that the geographical variance is largely due to a sort of 'legacy of the past', and that this is the reason for the educational delay from which the South suffered.

Regarding the first interpretation, while it would be wrong to lay the entire blame on the South's school system, it is necessary to bear in mind its numerous shortcomings and inadequacies - both material and otherwise. The main material deficiencies are not due simply to the lack of 
Table 5. Multiple linear regression, dependent variable: literacy proficiency score

\begin{tabular}{|c|c|c|c|c|}
\hline & & Coef. & Std.Err. & $\operatorname{Pr}>|t|$ \\
\hline \multicolumn{5}{|c|}{ Sex (ref. Male) } \\
\hline & Female & -1.541 & 1.294 & 0.234 \\
\hline \multicolumn{5}{|c|}{ Age (ref. $36-45$ years old) } \\
\hline & 16-25-years old & 1.558 & 2.620 & 0.052 \\
\hline & 26-35-years old & -1.373 & 1.774 & 0.439 \\
\hline & 46-55-years old & -3.919 & 1.703 & 0.021 \\
\hline & 56-65-years old & -16.654 & 2.066 & 0.000 \\
\hline \multicolumn{5}{|c|}{ Macro-region (ref. North-West) } \\
\hline & North-East & 15.317 & 3.043 & 0.000 \\
\hline & Central Italy & 14.621 & 3.134 & 0.000 \\
\hline & South and Islands & -3.059 & 2.600 & 0.085 \\
\hline \multicolumn{5}{|c|}{ Educational level (ref. Low) } \\
\hline & Medium & 26.946 & 2.854 & 0.000 \\
\hline & High & 42.140 & 3.979 & 0.000 \\
\hline \multicolumn{5}{|c|}{ Profession (ref. Elementary occupations) } \\
\hline & Highly qualifed professionals & 21.491 & 3.303 & 0.000 \\
\hline & Clerks and technicians & 14.441 & 2.957 & 0.000 \\
\hline & Skilled manual workers & 2.696 & 2.682 & 0.362 \\
\hline & Students & 27.915 & 3.862 & 0.000 \\
\hline & Fulfilling domestic tasks & 9.165 & 3.147 & 0.004 \\
\hline & Unemployed & 5.115 & 3.030 & 0.091 \\
\hline & Retired & 10.450 & 3.486 & 0.401 \\
\hline \multicolumn{5}{|c|}{ Father's educational level (ref. Low) } \\
\hline & Medium & 4.945 & 1.630 & 0.002 \\
\hline & High & 12.043 & 2.841 & 0.000 \\
\hline \multicolumn{5}{|c|}{ Macro-region*Educational level } \\
\hline & North-East*Medium & -4.364 & 3.975 & 0.451 \\
\hline & North-East*High & -9.162 & 5.280 & 0.635 \\
\hline & Central Italy*Medium & -10.034 & 4.159 & 0.487 \\
\hline & Central Italy*High & -13.324 & 5.235 & 0.847 \\
\hline & South and Islands*Medium & -7.517 & 3.445 & 0.485 \\
\hline & South and Islands*High & -16.944 & 4.670 & 0.613 \\
\hline Constant & & 226.675 & 3.640 & 0.000 \\
\hline R-sq & & \multicolumn{3}{|c|}{0.253} \\
\hline $\mathrm{N}$ & & \multicolumn{3}{|c|}{3,926} \\
\hline
\end{tabular}

Source: Authors' calculations from the PIAAC dataset (2011-2012). 
financial resources, but to how these resources are used. They are in fact earmarked for current spending to a greater extent than is the case in other macro-regions, meaning that there are lower investments in school maintenance, libraries and laboratories. Some authors (Bratti, Checchi and Filippin 2006) have found that the of skills is positively associated with capital expenditure rather than expenditure on teaching staff. They also note that equipment makes more difference than the number of teachers and/or their salary. Other scholars (Bettoni, Burgarella and Checchi 2006) argue that the regional divide in the Programme for International Student Assessment (PISA) data is correlated with lower expenditure on teaching. Still others (Bianchi, Gattei and Zoppi 2006) associate the higher dropout rates in the Southern regions with the schools' poor physical condition. It is well known that school buildings in the South are in worse condition than those in the rest of Italy, which are themselves far from perfect. It should be noted that the prime minister's creation of a 'Mission for coordinating and boosting improvements to school buildings' - despite having had the merit of establishing a single source of financing for school safety and maintenance to which funding applications can be made directly - has effectively penalised administrations with fewer planning skills. These inadequacies, which we will not discuss in further detail since they are well known, are accompanied by equally damaging 'school habits'. Southern Italian students' chronic tardiness and absences have a negative impact. The percentage of students who have never been late to school is higher in the North with peaks of 75 per cent in Veneto, in the self-governing provinces of Trento and Bolzano, in Emilia-Romagna and in Friuli-Venezia Giulia - than in the Southern regions: in Calabria, for example, only 54 per cent of students have never arrived late. As for attendance, 'ever present' students range from almost 80 per cent in Bolzano to a minimum of 37.7 per cent in Campania (OECD 2014). Teachers as well as students in the South show poor attendance records (Di Liberto and Sideri 2015). In addition, teachers' assessments tend to be unreliable: the grades they give their students are frequently very high, and do not match the rather low scores obtained in the standardised tests given by national and international surveys. ${ }^{9}$

The second interpretation attributes the gap in the stock of human capital to such factors as the South's far-from-flourishing civil society, the characteristics of its labour market, the spread of criminality, and the poor quality of the local political class. Usefully, this interpretation takes a broader view of the context. However, it risks yielding to the rhetoric of complexity, and overshadowing the action needed for change. It also risks giving in to culturalist postulates - undoubtedly seductive, but of scarce heuristic usefulness - which hold that the 'cultural matrix' and the 'basic personality' of each different cultural context determine the different social outcomes. This interpretation points out the weight of history on the present: the educational delay of the South, inherited from the pre-unification period and consolidated in the first post-unitary decades, has created real limitations, that is to say, situations of stasis from which it is difficult to escape (Faini and Sapir 2005). This caused inertia in the processes of human capital formation and in the choices of educational policy which, especially during the first 50 years after the unification of Italy, did not consider the widespread possession of solid citizenship skills a priority and have thus postponed the completion of literacy. The convergence in the schooling rates of the younger cohorts in the different macro-regions has in fact been realised (as shown in Table 1) only in the last decades. However, this convergence does not remedy the inevitable persistence of significant differences in the schooling rates of the older generations and therefore of the differences in the cultural capital offered by families, determining a phenomenon of intergenerational transmission of skills deficits (Ferrante 2017). In addition to these canonical interpretations, many others - no less important can explain why there is a lack of human capital in the South. First, it is observed that people with more human capital tend to seek better opportunities elsewhere. The PIAAC survey assesses 
Italians' competencies according to their area of residence and considers immigration from foreign countries, but not internal migration. It thus ignores the significant mobility that leads young people from the South to study and then work far from their place of birth. Data on cancellations of residency and registration as foreign residents show a constant increase in new emigration flows from Italy: the number of Italians abroad has risen from 3,106,251 in 2006 to 4,636,647 in 2015, a 49.3 per cent increase in ten years (ISTAT 2015). In 2014, the main regions where these flows originated included Lombardy $(18,425)$, Sicily $(8,765)$, Veneto $(8,720)$, Lazio (7,981), Piedmont (7,414), Emilia Romagna (7,285), Campania $(6,831)$, Tuscany $(5,967)$, Puglia (4,946), Friuli-Venezia Giulia $(4,831)$ and Calabria $(4,764)$. It is thus not only the regions of the South that are involved: the haemorrhage of human capital affects all of Italy. However, the greatest contribution to the sub-national variance in human capital is due to the traditional South-North migration axis. Between 1995 and 2013, 2.3 million people left the South to move to the Centre-North, an average of more than 120,000 a year. Unlike the flows observed between the 1950s and the 1970s, these migrations mostly concern educated people with a secondary school diploma or a degree. There has also been a steady increase in the emigration of the so-called 'excellences': in 2004, 25 per cent of graduates with the highest marks left the South, while three years later the percentage had jumped to almost 38 per cent (Impicciatore and Strozza 2016).

Furthermore, a lack of human capital is observed in the South because this area is locked in a vicious circle. The scarcity of skilled job opportunities - those that most of the better educated young people in the South move elsewhere to seek - does not stimulate others to undertake a long, expensive and demanding education. On the other hand, in the absence of qualified human resources, the economic system and public administration is unlikely to improve. The vicious circle that results is a cumulative, self-reproducing process: a trap with no way out.

Finally, there is a lack of human capital in the South because of the widespread conviction that education does not pay off. We do not know of any empirical evidence supporting this belief. However, it has been found that the rate of private return on education in Italy - estimated on the basis of the additional income that an individual receives on average by completing an additional year of study, net of personal costs incurred to achieve it - is lower than the OECD average. International comparisons apart, however, this does not describe the entire situation: the low return on investment is chiefly evident in the early stages of a career, not in subsequent ones. Above all, this conjecture is in fact far from applying to the South, where the return on education is higher than in the rest of Italy (Cingano and Cipollone 2009): the advantages associated with having a high level of human capital are even greater in areas with low percentages of highly skilled people, that is to say in the economically weakest parts of the country.

Evidently, the explanations and hypotheses presented are neither exhaustive nor mutually exclusive. They signal the presence of a plurality of factors ${ }^{10}$ whose joint influence causes multiplicative effects.

\section{And about the North-West?}

The low level of human capital in the North-West is the most unexpected finding that emerged from the PIAAC survey. The arguments regarding the South do not seem to apply to it. This finding is difficult to interpret, and no arguments or evidence can be marshalled to explain it that are even remotely comparable to those available for the South. In fact, while there is a vast scientific literature on the 'southern question', the North-West has been the subject of ambivalent attention. Dubbed the 'industrial triangle' (with the cities of Turin, Milan and Genoa at the vertices) because of the many major industries in the area, it has long been thought of as epitomising the North as a 
whole. Many decades passed before it was realised that the North-East has its own specific production model, with industries that are smaller but more widespread (Bagnasco 1977). Later, in a reversal of fortune, the North-West disappeared from the public debate and the political agenda, dissolved in the narrative of a unitary 'Great North' distinct from the other areas of the country proposed by the Lega Nord party (Scamuzzi 2001); in the description of the 'infinite city' (Bonomi 2004); or in the thematisation of the Po Valley city-region, understood as a network of cities, complementing each other and closely linked to the production centres (Pichierri and Perulli 2010). The North-West (but in particular, Piedmont and Liguria) still bearing the scars inflicted by the decline of Fordist industry and the social change it generated, has been addressed by a few specific studies (see, just to give some examples, Ferragutti 2005; Berta and Pichierri 2007), but deserves more extensive attention.

To return to the results of the PIAAC survey, the mediocre average competence score for the population surveyed in the North-West could result from a composition effect: the less educated, whose skills are similar (or worse) than those of the less educated in the South and Islands, lower the overall regional average. In particular, the lack of skills on the part of young people between the ages of 16 and 25 (see Table 3) and of those with educational qualifications up to high school diploma level (see Table 4) is surprising. Does this reflect shortcomings in the North-West's school system? The evidence is contradictory. As noted earlier, schooling rates are lower in the North-West than in the rest of Italy (see Table 1), but the quality of teaching seems adequate: the scores achieved by 15-year-old students in the North-West on the Programme for International Student Assessment (PISA) tests place them firmly in second place in the national rankings, after the North-East (in 2000, 2003, 2006, 2009 and 2012).

The PIAAC results are even more surprising because a previous survey in the Adult Literacy and Life Skills Survey (ALL), carried out in 2003, had not shown any particularly critical signs regarding the level of competence of the resident population of the North-West. This seems clear from the distribution of literacy proficiency scores in the five areas that were oversampled in the national ALL survey: Lombardy, Piedmont, the self-governing province of Trento, Tuscany and Campania (see Table 6).

Table 6. Mean literacy proficiency scores in some Italian regions

\begin{tabular}{|l|c|c|c|c|}
\hline & Mean & S.D. & Min & Max \\
\hline Lombardy & 231.70 & 55.67 & 60.40 & 420.37 \\
\hline Piedmont & 238.76 & 50.83 & 67.43 & 402.07 \\
\hline Province of Trento & 230.41 & 47.48 & 65.17 & 373.41 \\
\hline Tuscany & 229.82 & 48.48 & 69.72 & 388.75 \\
\hline Campania & 213.46 & 50.48 & 48.89 & 397.78 \\
\hline Italy & 229.63 & 55.64 & 23.76 & 420.37 \\
\hline
\end{tabular}

$\mathrm{F}=84335.79$ Sign. $=0.000$

Source: Authors' calculation from ALL dataset (2003).

How to explain such a serious deterioration of skills over a decade? The puzzle of the North-West results generates new questions. Piecing together this puzzle calls for refining research techniques and oversampling the regional populations. 


\section{Conclusions}

In the last few decades, formal education statistics have shown high rates of participation in the education system and an increase in the number of graduates in the southern regions of Italy, which historically have had lower levels of education than the rest of the country. These data appear to point to a growing convergence between the performance of the school system in the South and those in the other macro-regions. However, if we shift the focus from formal education to real education data, i.e., the skills that people actually possess and use in their daily life - in work as in free time - this process of convergence is incomplete. Greater participation in education has certainly had positive effects: the juvenile population is in fact better prepared than previous generations. However, improvements have been slow and small (the overall results for young people in the South are still poorer than those shown by young people in other Italian macro-regions).

These findings confirm the importance of formal education in building skills, and bode well for the outcome of the expansion of the school system in the South. The future stock of human capital in these areas could increase in the coming decades, provided that the conditions whereby it can show its potential are established. Indeed, 'political, institutional and legal arrangements are extremely important complements' to human capital (OECD 2001, 13). This means that territorial cohesion policies aimed at developing new economic market activities and collective services are needed. Delays or uncertainties in this area can cause serious damage, especially in an economic system such Italy's, which is weighed down by over 20 years of stagnating factor productivity, and unprepared for radical, incremental change. Nevertheless, the awareness of the importance of adopting system policies must not forget that the formation of human capital - dogged by historical weaknesses and severely jeopardised by current political inadequacies - now faces an absolute priority: improving the quality and the effectiveness of education institutions.

\section{Notes on contributors}

Alberto Baldissera was formerly professor of general sociology and president of the degree course in Educational Sciences at the University of Turin. His research interests and publications focus on the sociology of collective actions, labour and the economy, as well as social science methodology. He has also carried out research and teaching on the themes of sociology of education and evaluation of university systems.

Federica Cornali is researcher in sociology at the University of Turin. Her main research interests include education and human capital formation, focusing particularly on their relationship with social and economic development, and she is also interested in school effectiveness and education policy.

\section{Notes}

1. For reasons of alignment with the PIAAC results, the following education data are not the most up-to-date ones but those closer to the year of the administration of the tests.

2. At the European level, such objectives were present in the strategy of the Lisbon Agenda (European Council, 23 and 24 March 2000). Of the Agenda's five education and training objectives to be achieved by 2010 , three were quantitative: reducing early school leaving rates to below 10 per cent; increasing graduates in mathematics, science and technology by at least 15 per cent; increasing the share of young people completing upper secondary education to at least 85 per cent of the 22 -year-old population. The new programme expiring in 2020 also sets out school policy objectives centering on expansion: for example, it revives the goal, which had not been achieved during the previous programme, of reducing school dropout rates to below 10 per cent, while other objectives include bringing the percentage of children between the ages of four and six participating in early childhood education to at least 95 per cent, and bringing the share of 35-40-year olds with tertiary educational attainment to at least 40 per cent. 
3. The obbligo d'istruzione applies to young people between the ages of six and 16 . The requirement is fulfilled by attending the first cycle of education (i.e., the five years of primary school and three years of lower secondary school) and the first two years of upper secondary school or, alternatively, attending vocational education and training courses in facilities accredited by the regional governments or in subsidised technical schools.

4. The obbligo formativo applies after the age of 16 and is the 'right and duty to receive education and training until the attainment of a qualification lasting at least three years by the age of 18' (Legislative Decree $76 / 2005$, Art. 1). This requirement can be fulfilled by earning a high school diploma or by attending the first two years of high school, followed by a professional training course granting the qualification or working with an apprenticeship contract or other contract that includes training activities.

5. For 2000-2006, this fund made it possible to implement a National Operational Programme (PON) entitled 'The school for development', which promoted over 13,000 initiatives that furthered the development of the information society in Abruzzo, Basilicata, Calabria, Campania, Molise, Puglia, Sardinia and Sicily by supplying personal computers and encouraging the use of multimedia technologies. Similarly, the European Regional Development Fund (ERDF) financed the 'Learning environments' PON for 2007-2013, which sought to support educational innovation and quality in four regions (Calabria, Campania, Puglia and Sicily) and bridge the gap with other areas of the country and the European Union. The current 2014-2020 PON is entitled 'For the school - skills and learning environments'. Over 3 million euros are available for this programme, with more than half of the total provided by European Union funds. Regions lagging behind (Basilicata, Calabria, Campania, Puglia and Sicily) will receive two billion and 111.5 million euros, while 193.8 million euros are earmarked for the regions in transition (Abruzzo, Molise and Sardinia). The most developed regions (Emilia-Romagna, Friuli Venezia-Giulia, Lazio, Liguria, Lombardy, Marche, Piedmont, Tuscany, Umbria, Val d'Aosta and Veneto, the self-governing province of Bolzano and the self-governing province of Trento) will receive 714 million euros.

6. For Italy, the survey was carried out on behalf of the Ministry of Labour and Social Policies by the Institute for the Development of Professional Training for Workers (ISFOL). The sampling procedure (carried out by ISTAT) is illustrated in detail in the 'Methodological Appendix' of ISFOL 2014, 257. To carry out the analyses presented in this paper, the cases were weighed with the Final Full Sample Weight in order to rebalance the sample with reference to the Italian population.

7. ISFOL provides the national dataset including the macro-region classification variable 'Italy Macro Regions'. This variable is not present in the Italian dataset on the OECD website (http://www.oecd. org/skills/Piaac/publicdataandanalysis/). The OECD also neglects to mention the Italian sub-national sampling in the final report presenting the findings of the PIAAC survey (OECD 2016a). By contrast, the Italian sub-national sampling was cited in the final report on the survey preceding the Programme for the International Assessment of Adult Competencies, the Adult Literacy and Life Skills study (OECD 2011, 368). On that occasion, the regions concerned were oversampled. ISFOL did not respond to our request for clarification on regional sampling.

8. The differences between the mean values of literacy proficiency scores in the macro-regions are statistically significant - that is, linked to the variable that defines the groups - and are thus not attributable to mere randomness.

9. In 2015,788 out of 3896 honours awarded during high school final exams throughout Italy were given in Puglia. In the national rankings, Puglia is followed by Campania - which, with 12,000 fewer final-year students than Lombardy, has twice the number who graduated with honours (455) - and Sicily (372 honours).

10. Numerous other factors could still be mentioned. Among these are the agency and organisational capacity of teachers and school administrators (Pavolini et al. 2015).

\section{References}

Asso, F., L. Azzolina and E. Pavolini. 2015. L'istruzione difficile. I divari nelle competenze fra Nord e Sud. Rome: Donzelli.

Bagnasco, A. 1977. Tre Italie: la problematica territoriale dello sviluppo italiano. Bologna: Il Mulino.

Baldissera, A., A. Bianco and F. Cornali. 2012. Migliorare le competenze dei giovani del Mezzogiorno. Il caso della Sicilia. Acireale-Rome: Bonanno. 
Ballarino, G., N. Panichella and M. Triventi. 2014. 'School Expansion and Uneven Modernization. Comparing Educational Inequality in Northern and Southern Italy'. Research in Social Stratification and Mobility 36: 69-86.

Barone, C., R. Luijkx and A. Schizzerotto. 2010. 'Elogio dei grandi numeri: il lento declino delle disuguaglianze nelle opportunità d'istruzione in Italia'. Polis XXIV (1): 5-34.

Barone, C. and R. Guetto. 2016. 'Verso una meritocrazia dell'istruzione? Inerzia e mutamento nei legami tra origini sociali, opportunità di studio e destini lavorativi in Italia (1920-2009)'. Polis XXX (1): 5-34.

Berta, G. and A. Pichierri, eds. 2007. Libro bianco per il Nord Ovest. Dall'economia della manifattura all'economia della conoscenza. Venice: Marsilio.

Bettoni, C., M. Burgarella and D. Checchi. 2006. 'Educare con quali risorse? Investimenti e spese'. La Rivista delle Politiche Sociali 4: 31-47.

Bianchi, L., S. Gattei and S. Zoppi, eds. 2006. La scuola nel Mezzogiorno tra progressi e ritardi. Bologna: Il Mulino.

Bonomi, A. 2004. 'La città infinita'. In La città infinita, edited by Bonomi A. and A. Abruzzese, 13-34. Milan: Mondadori.

Bratti, M., D. Checchi and A. Filippin. 2006. 'Le competenze degli studenti italiani quindicenni. Il ruolo del divario sociale'. La Rivista delle Politiche Sociali 4: 93-111.

Breen, R. and J. Jonsson. 2007. 'Explaining Change in Social Fluidity: Educational Equalization and Educational Expansion in Twentieth-century Sweden'. American Journal of Sociology 112 (6): $1775-1810$.

Checchi, D. and V. Peragine. 2005. 'Regional Disparities and Equality of Opportunity: The Case of Italy'. IZA Discussion Paper 1874.

Cingano, F. and P. Cipollone. 2009. 'I rendimenti dell'istruzione'. Questioni di Economia e Finanza 53: 5-27.

De Fort, E. 1995. Scuola e analfabetismo nell'Italia del 900. Bologna: il Mulino.

Di Liberto, A. and M. Sideri. 2015. 'Se l'insegnante non va a scuola'. http://www.lavoce.info/archives/34561/ se-linsegnante-non-va-a-scuola/.

Eurostat. 2012. General Government Expenditure by Function. http://ec.europa.eu/eurostat/statisticsexplained/index.php/Government_expenditure_by_function.

Faini, R. and A. Sapir. 2005. 'Un modello obsoleto? Crescita e specializzazione dell'economia Italiana'. In Oltre il declino, edited by T. Boeri, 19-77. Bologna: Il Mulino.

Felice, E. 2012. 'Regional Convergence in Italy, 1891-2001: Testing Human and Social Capital'. Cliometrica 6: 267-306.

Ferragutti, P., ed. 2005. Osservatorio del Nord Ovest. Rapporti focalizzati 2004. Milan: Carocci.

Ferrante, F. 2017. 'La qualità dell'istruzione in Italia: un'eredità del passato?'. Scuola Democratica, 2: 343-366.

Foresti, M. and A. Pennisi. 2007. 'Fare i conti con la scuola nel Mezzogiorno. Un' analisi dei divari tra le competenze dei quindicenni in Italia'. Materiali UVAL 13.

Impicciatore, R. and S. Strozza. 2016. 'Lasciare il Mezzogiorno'. Il Mulino 1: 125-132.

ISFOL. 2014. PIAAC-OCSE. Rapporto nazionale sulle competenze degli adulti. Rome: ISFOL.

ISTAT. 2011. Conti economici regionali. Rome: ISTAT.

ISTAT. 2015. Annuario statistico italiano. Rome: ISTAT.

Manzo, G. 2009. La spirale des inegalités. Paris : Presses Universitaires de Paris Sorbonne.

Martin, J. 1992. Cultures in Organizations: Three Perspectives. New York: Oxford University Press.

Meyer, J.W., F.O. Ramirez and Y.N. Soysal. 1992. 'World Expansion of Mass Education, 1870-1980'. Sociology of Education 65 (2): 128-149.

OECD. 2001. The Well-being of Nations. The Role of Human and Social Capital. Paris: OECD Publishing.

OECD and Statistics Canada. 2011. Literacy for Life: Further Results from the Adult Literacy and Life Skills Survey. Paris: OECD Publishing.

OECD. 2013. OECD Skills Outlook 2013: First Results from the Survey of Adult Skills. Paris: OECD Publishing.

OECD. 2014. PISA 2012 Results: What Students Know and Can Do. Paris: OECD Publishing.

OECD. 2016a. Education at Glance 2016. Paris: OECD Publishing. 
OECD. 2016b. The Survey of Adult Skills: Reader's Companion, Second Edition. Paris: OECD Publishing.

Pavolini, E., G. Argentin, G. Barbieri, P. Falzetti and R. Ricci. 2015. 'L'influenza delle scuole del contesto locale sui divari territoriali'. In L'istruzione difficile. I divari nelle competenze fra Nord e Sud, edited by F. Asso, L. Azzolina and E. Pavolini. 81-126. Rome: Donzelli.

Pfeffer, F. 2008. 'Persistent Inequality in Educational Attainment and its Institutional Context'. European Sociological Review 24 (5): 543-565.

Pichierri, A. and P. Perulli. 2010. La crisi italiana nel mondo globale. Economia e società del Nord. Turin: Einaudi.

Pisati, M. 2002. 'La partecipazione al sistema scolastico'. In Vite ineguali. Disuguaglianze e corsi di vita nell'Italia contemporanea, edited by A. Schizzerotto, 141-186. Bologna: Il Mulino.

Scamuzzi, S. 2001. 'Il Nord-Ovest, o quel che ne sarà'. In Politica, istituzioni, sviluppo, edited by P. Fantozzi, 155-171. Soveria Mannelli: Rubbettino.

Schofer, E. and J.W. Meyer. 2005. 'The Worldwide Expansion of Higher Education in the Twentieth Century'. American Sociological Review 70: 898-920.

Triventi, M. and P. Trivellato. 2008. 'Le onde lunghe dell'università italiana. Partecipazione e risultati accademici degli studenti nel Novecento'. Polis XXII (1): 85-118.

Weick, K.E. 1976. 'Educational Organizations as Loosely Coupled Systems'. Administrative Science Quarterly 21 (1): 1-19.

\section{Italian summary}

Negli ultimi decenni si è assistito a un crescente interesse riguardo alla diffusione del capitale umano. A esso, infatti, è riconosciuto un ruolo sempre più rilevante nello stimolare lo sviluppo sociale ed economico. Questo contributo, dopo aver presentato la distinzione tra 'istruzione' - certificata dalla distribuzione dei titoli di studio - e 'competenza - vale a dire il livello di ciò che effettivamente le persone sanno fare con la parola e i numeri scritti - esaminerà la distribuzione di queste proprietà in Italia. Dagli esiti dell'analisi emerge che per quanto riguarda il livello di istruzione della popolazione lo storico divario tra Nord e Sud si sta progressivamente colmando, mentre è invece confermato un rilevante divario per quello che riguarda il livello di competenza acquisito. Emerge inoltre un risultato inatteso: il Nord-Ovest, un tempo riconosciuto come principale motore dello sviluppo economico italiano, mostra oggi una dotazione di capitale umano ridotta rispetto quello delle macro-regioni del Nord-Est e del Centro. Alla luce di queste risultanze, il miglioramento dell'efficacia del sistema d'istruzione nonché la creazione adeguati dispositivi politici, istituzionali e giuridici che favoriscano lo sviluppo del capitale umano, paiono per l'Italia una priorità assoluta. 